Finisterra, XXXVI, 71, 2001, pp. 153-156

\title{
CONFERÊNCIA ANUAL DA REAL SOCIEDADE DE GEOGRAFIA E DO INSTITUTO DOS GEÓGRAFOS BRITÂNICOS - 2001
}

\author{
Alina Esteves ${ }^{1}$
}

A conferência de 2001 da Real Sociedade de Geografia e do Instituto dos Geógrafos Britânicos (Royal Geographical Society - Institute of British Geographers) decorreu entre os dias 2 e 5 de Janeiro na cidade inglesa de Plymouth, localizada 350 quilómetros a SW de Londres. O evento deste ano foi organizado pelo Departamento de Ciências Geográficas da Universidade de Plymouth, que orienta grande parte da sua investigação para quatro grandes áreas temáticas: o ambiente Quaternário, a biogeografia e gestão ambiental, as áreas em desenvolvimento, e as mudanças sociais e económicas na Europa. A Universidade de Plymouth acolhe também o Centro Nacional para a Geografia, Terra e Ciências Ambientais. O grande investimento que os investigadores do Departamento realizam no domínio das questões ambientais e da Geografia Física orientou de certa forma a escolha dos dois grandes temas da conferência: o Risco e a Inovação, por um lado, e a Sociedade e o Mar, por outro.

Defendendo a lógica da difusão de resultados e partilha de experiências, a organização da conferência promoveu a realização de sessões de trabalho, em que participassem investigadores pertencentes a vários Grupos de Investigação. Este ano, com um total de 28 Grupos de Investigação, foram apresentadas 435 comunicações repartidas por 49 sessões de trabalho, números muito semelhantes aos da conferência do ano transacto. As sete palestras proporcionadas aos participantes durante a hora do almoço ou ao fim do dia obedeceram às duas temáticas principais da conferência e focaram essencialmente questões ligadas ao risco e à capacidade de previsão da ocorrência de catástrofes naturais. Sir Crispin Tickell realizou uma interessante apresentação sobre as catástrofes «vindas do céu» apresentando as perspectivas de defesa planetária contra meteoritos. O Professor Julian Hunt abordou o tema da predição dos perigos como uma forma de reduzir o risco, ao passo que o Professor David Jones dissertou em torno da Geografia e dos envolventes arquipélagos do perigo e do risco. A Geografia no século XXI foi o tema da prelecção do Professor Peter

\footnotetext{
1 Assistente da Faculdade de Letras, Universidade de Lisboa. Investigadora do Centro de Estudos Geográficos. E-mail: alinaesteves@eurodivisal.com
} 
Haggett, e o Dr. Richard Howitt debruçou-se sobre o papel da Geografia na educação dos jovens para a justiça.

Na sessão dedicada à gestão ambiental na Península Ibérica, ficou bem patente a cooperação científica existente entre as instituições universitárias do Reino Unido e as suas congéneres portuguesas e espanholas. Com efeito, foram apresentadas várias comunicações onde se caracterizaram os processos de desertificação que afectam o Alentejo e a Extremadura espanhola, identificando actores-chave e possíveis respostas para o problema. Adoptando uma perspectiva crítica em relação à sua eficácia, foram divulgados programas de reflorestamento para combater a erosão do solo na região de Múrcia, estratégias de turismo ecológico apoiadas na manutenção de sistemas de irrigação tradicionais e de paisagens culturais na Serra Nevada (Andaluzia) e as perspectivas futuras do sector agro-florestal em Portugal.

Seguindo os grandes temas da Conferência, foi organizada uma sessão sobre o património e o mar onde se debateram as melhores soluções para revitalizar antigas zonas portuárias já desactivadas, os eco-museus marítimos como elementos inovadores e de manutenção do património das regiões costeiras, e o marketing de zonas ribeirinhas de modo a torná-las atraentes para novos residentes.

O Grupo Britânico de Geomorfologia dedicou uma sessão ao estudo da avaliação do risco no caso dos deslizamentos, inundações e outras catástrofes naturais em regiões tão variadas como o Sudeste da Espanha, o Norte da China, o Noroeste da Islândia e as terras altas da Escócia.

«Vivendo com a catástrofe» foi o título da sessão organizada pelos Grupos de Estudo das Áreas em Desenvolvimento e das Áreas de Montanha, onde foram apresentados interessantes resultados de investigações desenvolvidas no Mar de Mármara após os terramotos que afectaram a Turquia, as consequências das recentes escorrências de lama nas montanhas Tian Shan no Cazaquistão e um trabalho sobre o estado da avaliação do risco de construção em áreas de permafrost na Europa Central.

A sessão sobre os ambientes em degradação promovida pelo Grupos da Biogeografia e da Geomorfologia abordou a degradação dos mantos de lava na ilha de Lanzarote por colónias de líquenes, os efeitos da vegetação na estabilização das margens dos rios, o papel dos processos biológicos na erosão das costas calcárias sub-tropicais na Austrália e os movimentos das vertentes nos vales do País de Gales datados através da evolução da vegetação.

A sessão conjunta do Grupo da Geografia Social e Cultural e do Grupo da História e Filosofia da Geografia foi repartida por dois módulos, o primeiro dedicado à paisagem, seu significado e temporalidade, e o segundo aos limites temporais da geografia teórica.

O Grupo de Investigação da Geografia dos Transportes subordinou a sua sessão ao risco associado ao transporte de passageiros e mercadorias em difíceis condições meteorológicas, ao perigo do transporte de resíduos nucleares, às estratégias do governo britânico sobre a segurança rodoviária até ao ano 2010 e à participação dos utentes no planeamento dos transportes. 
Os empreendimentos turísticos das áreas costeiras, a utopia e a cultura foram os temas eleitos pelo Grupo de Investigação do Lazer e do Turismo. Os investigadores apresentaram interessantes comunicações sobre as alterações registadas nos tradicionais destinos turísticos do litoral dos condados da Cornualha e de Devon devido aos processos de restruturação económica, registados nos últimos anos. O projecto Eden, recentemente aberto ao público na Cornualha, pretende recriar um conjunto de vários ecossistemas existentes no planeta Terra, promovendo o turismo ecológico e concretizando o anseio humano de recriar uma utopia.

O Grupo de Investigação da Geografia Histórica abordou as questões da colonização europeia dos territórios africanos, australianos e neozelandeses, focando essencialmente o levantamento cartográfico do terreno, a ocupação humana, a exploração dos recursos humanos e naturais (florestais e minerais).

Os problemas da difusão do vírus HIV e da SIDA, principalmente nas áreas urbanas da Zâmbia, Malawi e Uganda e entre a população mais jovem, a exposição aos raios ultravioleta $\mathrm{B}$ e o aumento dos casos de hiper-tensão arterial no Reino Unido, e a repartição intra-urbana dos acidentes com crianças na cidade britânica de Norwich, foram temas abordados na sessão conjunta dos Grupos de Investigação da Geografia da População e da Geografia da Saúde.

O Grupo de Investigação dos Métodos Quantitativos organizou uma sessão dedicada ao tema da construção de modelos espaciais para apoio à decisão em áreas tão variadas como a saúde e provisão de serviços sociais, a localização de serviços financeiros e o comércio retalhista, a expansão urbana e os movimentos migratórios dentro do Reino Unido. Notou-se, este ano, um recrudescimento do interesse por estas metodologias, bem visível não apenas no número de comunicações apresentadas, mas também na variedade das origens geográficas dos participantes, reveladoras da intensa cooperação científica entre as instituições universitárias de vários países.

O fórum dos jovens investigadores da Geografia Rural debateu a problemática do turismo rural sustentável na Irlanda, a industrialização do mundo rural e o empresarialismo nos condados de Warwickshire e Devon, a geografia da agricultura biológica no Reino Unido e a crescente importância dos mercados de produtores que comercializam directamente os seus produtos animais e vegetais aos consumidores, apostando fortemente na qualidade e confiança do produto.

Os conferencistas podiam optar por duas excursões, A regeneração do vale do rio Tamar e Stonehouse: o Real Estaleiro Naval. Foi também preparado um guião anotado que permitia aos conferencistas realizarem um passeio pedestre no centro histórico de Plymouth, em qualquer momento da conferência, e observarem os principais monumentos e pontos de interesse desta cidade portuária.

A primeira visita realizou-se ao longo do vale do rio Tamar, importante via fluvial que estabelece a fronteira natural entre os condados de Devon e da Cornualha. O objectivo da visita foi mostrar aos participantes o tipo de regeneração económica e social que o Conselho do Condado da Cornualha tem estado 
a desenvolver para revitalizar uma área que, no século XIX, foi uma das principais regiões de extracção de cobre do mundo, mas que após o declínio desta actividade, entrou em forte recessão. As estratégias passam pelo investimento em trabalhos de arqueologia industrial com o intuito de recuperar o património construído desse período, promovendo e divulgando visitas de carácter recreativo e pedagógico junto das escolas, das populações e dos turistas que visitam a região. Os fundos da União Europeia e das agências Regionais de Desenvolvimento têm sido fundamentais na recuperação de um conjunto de infra-estruturas que facilitam a realização de percursos nas vilas históricas.

O Real Estaleiro Naval, localizado na margem esquerda do estuário do rio Tamar, foi construído em 1834 com o objectivo de coordenar e assegurar o abastecimento dos navios da Frota Real. Contudo, o difícil acesso por terra e a ausência de ligação directa ao caminho de ferro fizeram com que o estaleiro fosse subutilizado durante a sua vida activa. Nos anos noventa (entre 1993 e 1998) foi desactivado e passou a ser administrado por uma agência governamental que, usando fundos europeus e estatais, começou a promover melhorias ao nível das infra-estruturas para uma nova utilização onde estão incluídos hotéis, restaurantes, lojas e habitação. Se o arranjo da frente ribeirinha tem registado progressos visíveis, principalmente nos acessos ao cais e na habitação, já a recuperação do Real Estaleiro tem sido lenta e morosa em parte devido ao elevadíssimo custo da operação.

A Escola de Geografia da Queen's University de Belfast na Irlanda do Norte será a organizadora da conferência de 2002, onde se irão debater quatro temas principais: as Migrações, a Complexidade e o Caos, a Paisagem (procurando estabelecer a ligação entre Geografia Física e Geografia Humana) e Cidades Divididas, Comunidades Divididas. 